\title{
Technology, Selection, and Training in Call Centers
}

Citation for published version (APA):

Sieben, I. J. P., de Grip, A., Longen, J., \& Sorensen, O. (2007). Technology, Selection, and Training in Call Centers. ROA. ROA Research Memoranda No. 004 https://doi.org/10.26481/umaror.2007004

Document status and date:

Published: 01/01/2007

DOI:

10.26481/umaror.2007004

Document Version:

Publisher's PDF, also known as Version of record

\section{Please check the document version of this publication:}

- A submitted manuscript is the version of the article upon submission and before peer-review. There can be important differences between the submitted version and the official published version of record.

People interested in the research are advised to contact the author for the final version of the publication, or visit the DOI to the publisher's website.

- The final author version and the galley proof are versions of the publication after peer review.

- The final published version features the final layout of the paper including the volume, issue and page numbers.

Link to publication

\footnotetext{
General rights rights.

- You may freely distribute the URL identifying the publication in the public portal. please follow below link for the End User Agreement:

www.umlib.nl/taverne-license

Take down policy

If you believe that this document breaches copyright please contact us at:

repository@maastrichtuniversity.nl

providing details and we will investigate your claim.
}

Copyright and moral rights for the publications made accessible in the public portal are retained by the authors and/or other copyright owners and it is a condition of accessing publications that users recognise and abide by the legal requirements associated with these

- Users may download and print one copy of any publication from the public portal for the purpose of private study or research.

- You may not further distribute the material or use it for any profit-making activity or commercial gain

If the publication is distributed under the terms of Article $25 \mathrm{fa}$ of the Dutch Copyright Act, indicated by the "Taverne" license above, 


\title{
Technology, Selection, and Training in Call Centers
}

\author{
Inge Sieben \\ Andries de Grip \\ Jessica Longen \\ Ole Sørensen
}

ROA-RM-2007/4

August 07

\author{
Research Centre for Education \\ and the Labour Market \\ P.O. Box 616 \\ 6200 MD Maastricht \\ The Netherlands \\ E-mail: $\quad$ mailto:secretary@roa.unimaas.nl \\ Internet: $\quad$ http://www.roa.unimaas.nl \\ Maastricht University \\ Faculty of Economics and Business Administration
}


The ROA Research Memorandum Series was created in order to make research results available for discussion, before those results are submitted for publication in journals. 
ROA-RM-2007/4 》 http://www.roa.unimaas.nl/resmem.htm

\section{Abstract}

\section{Technology, Selection, and Training in Call Centers}

In this paper, we study the relationships between technology, selection, and training for newly hired and for more experienced workers in call centers. Employing survey data on call centers in 14 countries, we distinguish between different technologies. Our findings confirm the more generic literature that information and communication technology (ICT) increases training investments. However, we find that specific technologies have different effects on training as well as on informal learning in the first year. It is particularly workflow technologies that drive training demands in call centers. In contrast, interaction automation technologies and enhanced interaction technologies only lead to more ongoing training, and interaction automation technologies have a negative relationship with informal learning in the first year. Moreover, we find that more selective hiring practices partially mediate the relationship between ICT and training. This suggests that call centers with high training demands induced by ICT recruit a workforce with higher returns to training.

JEL Codes: M53, M51, J24

Keywords: Training, technology, recruitment

For helpful comments on earlier drafts of this paper, the authors would like thank Rose Batt, Ursula Holtgrewe, and participants in the ROA seminar, Maastricht University, September 12, 2006. The data from the Global Call Center Project was supported by funds from the Russell Sage Foundations. For replication purposes, copies of the computer programs used to generate the results in the paper are available from Inge Sieben (i.sieben@roa.unimaas.nl). The authors thank Rose Batt, Lex Borghans and Jasper van Loo for their comments on earlier versions of this paper. 
Inge Sieben

ROA

P.O. Box 616

6200 MD Maastricht

The Netherlands

i.sieben@roa.unimaas.nl

Jessica Longen

Graduate School Topology of Technology

University of Technology Darmstadt

Magdalenenstr. 10, TU-Kraftwerk Raum S1

07/204, 64283 Darmstadt

longen@ifs.tu-darmstadt.de
Andries de Grip

ROA

P.O. Box 616

6200 MD Maastricht

The Netherlands

a.degrip@roa.unimaas.nl

Ole Sørensen

NRCWE

Lersø Parkallé 105

2100 Kopenhagen

Denmark

ohs@arbejdsmiljoforskning.dk 


\section{Introduction}

Research has shown that information and communication technology (ICT) has led to an increase in the demand for skills (e.g. Autor, Katz, and Krueger, 1998). Autor, Levy, and Murnane (2003) found that computerization is associated with declining demands for routine tasks and increased demands for non-routine cognitive tasks (cf. Spitz-Oener, 2006). Firms can meet these skill demands by further investments in the human capital of their workforce, although there might be a multiplicity of equilibria (Acemoglu, 1997).

Bartel and Sicherman (1998) found that employer-provided training is indeed positively related to the introduction of new technologies. However, much of the existing research is based on aggregated data, whereas the existing firm level research often is based on cross-industry studies forcing analysts to examine general and broadly defined measures of ICT that may have different effects in different industrial settings. Our focus on one narrowly defined sector of industry - the call center sector - enables us to investigate the relationship between ICT and training in more detail by distinguishing three specific types of call center technologies: interaction automation technologies, enhanced interaction technologies, and workflow automation. In contrast to conventional media accounts, employers and industry representatives view the call center industry as a knowledge intensive sector that requires skilled employees. It is argued that high state of the art information and communication technologies (ICT), together with market driven incentives such as more demanding customers, a growing focus on call quality, and an increase in the number of business-to-business and sales channels, have led to an increase in the skill requirements of these jobs. Moreover, these skills are relatively specific to call centers, suggesting that training and employee development are key issues in managing these operations. Given the importance of training in this sector, it is remarkable that the growing body of literature on call centers pays little attention to this issue. 
In this paper, we bridge this gap by focusing on the relationship between ICT on the one hand, and skill acquisition strategies (selection and training) on the other. ICT is crucial in the production process of call centers, and there are important differences in the technologies used and the skills demanded (Deery and Kinnie 2004). In addition, call centers are rather new firms that are less restricted by historically grown structures, and therefore free to organize their employee development in an optimal way. ICT plays a crucial role in this, as it both triggers skill demands and enables the efficient delivery of training programs.

We will analyze at the workplace level whether these technologies are associated with training of both newly hired workers and more experienced workers. Newly hired call center agents usually are extensively trained before they start working. The main reason for this is that call center work is quite specific in its nature and hardly any vocational training exists in formal education. Therefore, call centers often move out of institutionalized training paths, even in countries with highly developed institutions of vocational training like Germany, and offer extensive internal training to call center agents. Next to initial training programs, call centers usually invest in ongoing training for their more experienced agents, for example to inform them about new products or product updates, or to improve their sales techniques. In addition, informal or on-the-job learning is highly important in call centers. Most newly hired call center agents are involved in an intensive period of mentoring, where more experienced workers or supervisors sit next to them and listen in on their calls in order to give feedback and help with customer interactions. To provide a comprehensive picture of skill development in call centers, we will pay attention to formal initial and ongoing training, as well as to informal learning ${ }^{1}$ of call center agents. Moreover, we will study the mediating effect of selective hiring. If the use of ICT increases the need to invest in workers' training, call centers will probably select applicants with the

1. Information on informal training is limited to the first year, in which call center agents receive the most informal training. 
highest trainability and commitment to stay with the firm. Therefore, call centers with higher training demands due to the use of ICT will have more severe selection and recruitment practices, which give them more solid grounds for their training investments. As selective hiring thus is positively related to the use of advanced technologies as well as to training investments, the impact of ICT on training could be mediated by selective hiring.

In this paper, we will thus focus on the following research questions: (1) Is call center training for newly hired workers and for more experienced workers related to the use of different information and communication technologies, and (2) is there any mediating effect of selective hiring on this relationship? To answer these questions, we employ the international dataset of the Global Call Center Project based on surveys among call centre managers. We will use the data of fourteen countries: Austria, Brazil, Canada, Denmark, France, Germany, Ireland, Israel, Korea, Poland, Spain, Sweden, United Kingdom, and the United States. When studying the relationships between ICT, selective hiring, and training in call centers, we will focus on the 'core' employees working in call centers, i.e. call center agents.

The structure of this paper is as follows: First, we discuss the relevant theoretical and empirical literature and develop hypotheses about the relationship between ICT, selection, and training in call centers. After a discussion of our data and methods of analysis, we present our estimation results. We conclude with a discussion of the main implications.

\section{New Technology and the Demand for Skill}

In the general literature on the impact of ICT on the demand for skill, two different views have emerged. On the one hand, some argue that ICT is a substitute for workers who perform simple or well-defined tasks (Cooley 1986; Shaiken 1985). On the other hand, others argue that ICT complements work processes that involve more difficult 
tasks such as problem solving and complex communication activities (Kern and Schuhmann 1984). In either case, ICT increases the demand for skill. Several studies found that, in general, technology increases the complexity of jobs (such as Autor, Levy and Murnane 2003; Doms, Dunn and Troske 1997; Athey and Stern 2002; Spitz-Oener 2006) and the skill level of workers (such as Keefe 1991; Groot and de Grip, 1991). Other researchers, however, argue that new technologies can also 'downgrade' the skill content of jobs (Spenner 1985; Goos and Manning 2007) which has led to a polarization of skill demands.

As Levy and Murnane (2004:30) state: "Computers excel at the rapid application of rules" and their fast processing of calculations. This means that computers can substitute for a human agent if customers' requests are simple, such as "I want to buy two black chairs, product number 01234 . They should be delivered at..."; or "Please tell me the monthly pay rate for a mortgage of...”. But in cases where perceptual problems, contextual knowledge, or feelings are involved or where numerous exceptions apply, the substitution of a human agent by a machine is complicated or impossible. Computers are limited in their capacity to understand meaning, and therefore human interactions with a computer only work within a limited framework of rule-based selections (Suchman 1999). Therefore, in a computer-based dialogue, customers only are allowed a limited number of response categories. In cases where the computer cannot substitute for humans, it can often complement human action by providing a complex set of data that may be handled by the service representative. In sum, following Levy and Murnane (2004), computers may be used to automate away simple, repetitive, rule-based tasks or calculations. However, a range of activities from non-routine, manual tasks to expert knowledge have to be left to humans (cf. Goos and Manning, 2007). This means that whether ICT affects the demand for skill positively or negatively is an empirical question that has to be answered with regard to specific types of technologies and tasks. However, the overall picture in the US is that the demand for skill is increasing because jobs entailing expert thinking and complex 
communication are increasing, whereas routine manual and cognitive jobs are declining due to the introduction of ICT (Levy and Murnane 2004).

Companies can deal with the increased demands for skills related to technology by selective hiring and by investing in training. Several studies show empirical evidence that technology is related to selective hiring and higher investments in employerprovided training. Bartel and Sicherman (1998) find that indicators for technological change are positively related to indicators for the number of hours of employerprovided training in the US. Furthermore, US firms that invest in ICT are more selective and train a higher fraction of their workers than less ICT-intensive firms (Brynjolfsson and Hitt 1998; Bresnahan, Brynjolfsson, and Hitt 2002). Implementation of new technologies in Canadian manufacturing firms increased the level of required qualification and stimulated firms to invest in training (Baldwin, Gray, and Johnson 1995; Baldwin and Peters 2001). Similar results are found in a study on Italian manufacturing firms (Giuri, Torrisi, and Zinovyeva 2006), while German panel data from business related and distribution service firms also show that ICT usage fosters incentives for firms to invest in training (Hempell 2003).

We now turn to the implications of this general literature for the specific context of call centers. Call centers make more intensive use of information and communication technologies than firms in most other industry sectors. The effectiveness and quality of service work is therefore closely related to the development of appropriate skills required for an optimal use of ICT by the 'core workers' (cf. Osterman 2004 2000) in call centers: call center agents. This dependence on technology might affect the skill demands in call centers, which is reflected in both training needs and recruitment practices. As far as we know, there are no empirical studies on the relationship between ICT and training participation in call centers. Most of the literature on call center technology is related to its potential to control and monitor call center agents (Fernie and Metcalf 1998; Taylor and Bain 1999; Holman, Chissick and Totterdell 2002; Callaghan and Thompson 2002). Other strands of literature are much more 
normative, as they are for example describing how a specific technology should be implemented (Gherardi 1999; Cena and Torre 2006). It thus can be inferred that the use of ICT in call centers will increase the demand for skill, and we will formulate our hypotheses according to this standard expectation. However, from our case-study research ${ }^{2}$ we learned that there may be different relationships based on differences in specific types of technologies. We will therefore distinguish between three kinds of technologies, which are heavily used in call centers: Interaction automation technologies, workflow automation technologies and enhanced interaction technologies.

\subsection{Interaction Automation Technologies}

One important set of call center technologies are those that foster the automation of the customer interaction or parts of the interaction with the customer. Relatively simple inquiries can be completed without contact with a human agent (account information, reporting of data, information on opening hours) and also reception and switchboard services can be automated with computer-based redirection of calls. Interaction automation can be realized through the implementation of Voice Response Units (VRU), Interactive Voice Response (IVR) systems, and speech recognition systems. VRU is a system for conveying recorded messages; IVR makes is possible for customers to interact with the information system via touch-tone telephone keys. Speech recognition allows for two-way communication between the computer and the customer using synthetic speech messages.

The use of these interaction automation technologies can affect the skill requirements of jobs, and in turn, training, through different scenarios. Automation increases the demand for skill and training by working as a substitute for simple, repetitive tasks

2. In all countries, several case studies of in-house and subcontracting call centers in different industries were made, which included extensive interviews with general managers, HR managers, IT specialists and agent supervisors. 
and leaving the more complex tasks for employees to carry out (Richardson and Gillespie 2003). Others argue that interaction automation technologies also may be used to separate incoming calls by level of complexity and assign different workers to jobs with different skill requirements, thereby creating more fragmented or narrow jobs. Call centers that segment customers by their value added, for example, may use interaction automation technologies for segmentation, such that workers serving the mass market handle simpler requests and those serving business clients handle more complex ones (Batt, Hunter, and Wilk 2003). This implies that the general demand for skill would be lowered.

These different scenarios make that it is not easy to theoretically predict the overall relationship between customer automation technologies and training, and leave it to be an empirical question. However, we will formulate our hypothesis according to the standard expectation mentioned earlier that ICT in general is associated with higher levels of training for both newly hired workers and more experienced workers. This leads to the following hypothesis:

H1: Interaction automation technologies are positively related to the provision of initial training, informal learning in the first year, and ongoing training.

\subsection{Workflow Automation Technologies}

Like interaction automation technologies, workflow automation technologies are used to automate and standardize work processes. However, workflow technologies focus on the internal organization of work. Call center's workflow management systems automate the distribution of calls and the flow of tasks, enable skill based routing, and facilitate resource planning and staffing. Regarding the relationship with skills and training, one scenario is that call centers use skill based routing to link specific customer groups or types of inquiries to specific employee groups, thereby creating more fragmented or narrow jobs (Batt, Hunter, and Wilk, 2003). However, another scenario is that workflow automation increases call centers' overall ability to handle complex tasks that involve several call center agents and repeated customer 
interactions, which can be expected to raise the skill and training requirements of jobs. Furthermore, agents have to be trained to interact with the workflow systems. Therefore, we will again formulate our hypothesis according to the expectation that ICT leads to more training for both newly hired workers and more experienced workers, which is reflected in the following hypothesis:

H2: Workflow automation technologies are positively related to initial training, informal learning in the first year, and ongoing training.

\subsection{Enhanced interaction Technologies}

Enhanced interaction technologies include media blending, electronic customer relationship management (E-CRM) systems, and web-enablement. 'Media blending' allows call center agents to use a mixture of media to interact with customers including integrated use of e-mail, fax, phone, electronic chat, etc. We expect these technologies to be positively related to the demand for skill, as agents must master several types of technical systems and communication skills, such as writing skills and social interaction skills. Electronic CRM systems are important for call centers that have repeated interactions with the same customers because agents can retrieve and store information about each interaction with the customer in these systems. Thus, customer interactions can be personalized even when the customer interacts with different agents. The complexity of CRM systems often requires multi-tasking skills agents often have to talk to the customer and at the same time search for and assess records of prior customer contacts, fill in new customer data, and log information. Finally, web-enablement is a technology that enables employees to use intra- and Internet sources, such as knowledge databases, joint browsing, chat, etc. This increases both the variety and the complexity of customer interactions. Therefore, enhanced interaction technologies will increase the demand for skill in call centers, which is expected to affect training. Hence, we propose the following hypothesis:

H3: Enhanced interaction technologies are positively related to in initial training, informal learning in the first year, and ongoing training. 


\subsection{Selective Hiring Strategies}

When the use of more advanced technologies increases the need to invest in workers' training, firms have an incentive to select those workers who are most trainable and who are most committed to stay with the firm in order to reap the benefits from their training efforts. Call centers that train their agents face a large risk of losing these training investments when agents leave the firm, as turnover rates in the call center sector are notoriously high. Therefore, call centers with heavy training demands are likely to select employees who fit the organization best as these employees will stay longer in the firm. Selective hiring strategies usually focus on workers' competencies as well as behaviors and attitudes (cf. Becker and Huselid 1999). Particularly systematic selection tests, such as psychometric tests or aptitude tests, will enable call centers to hire the agents who have the best match with the firm and the contents of their job (Terpstra and Rozell 1993). Moreover, call centers that invest in the training of their agents will select the better qualified employees from the existing labor pool available, because the trainability of these employees is usually higher (Thurow 1975).

In labor economics literature on the determinants of training, many authors found a complementarity between employees' level of initial education and their training participation due to the higher trainability of more skilled people (e.g. Heckman 2000). Other researchers, however, found that although a higher level of education in general contributes to a higher probability of training, this is not the case when workers are overeducated for their job (Sicherman 1991; Hersch 1991; Van Smoorenburg and Van der Velden 2000). This indicates that part of workers' entry training may be a substitute for initial education; i.e. training enables those who are lower educated to acquire skills that the higher educated already acquired in initial education. However, providing training for call center agents will not be a substitute for their initial education, because the skills demanded in call centers are typically skills that are not acquired in initial education, such as mastering several types of technical systems, the use of intra- and internet sources, product and firm knowledge, 
social interaction skills (customer friendliness, negotiation and conversational techniques, and dealing with anger and aggression), complex problem solving, and telephonic sales techniques (cf. Sieben and De Grip 2004). These types of skills require employers to provide specific training and coaching to new recruits, and to further develop these skills in ongoing training.

The call center sector is therefore characterized by very large training investments in on-the job and off-the-job training. In the countries included in our analyses, call center agents have on average 22 training days in the first year of their appointment, and almost 10 days of ongoing training in the following years. This means that the opportunity costs of training (i.e. the time that workers are not productive) are about $9 \%$ of total labor costs in the first year of employment and about $4 \%$ in the following years. This is much higher than in other sectors of industry. In their extensive study on 25 European countries, for example, Brunello, Garibaldi, and Wasmer (2006) found that total training costs (i.e. opportunity costs and direct costs of training) range from $0.8 \%$ of the total labor costs in Poland to $3 \%$ in Denmark.

To summarize, when call centers that use more advanced technologies have to make large investments in training their call center agents in order to meet the required quality of their services, it can be expected that they are selective when hiring new workers. The selection process will particularly focus on recruiting agents with a high trainability as well as a lower probability to quit. We therefore expect that selective hiring is a prerequisite for training investments, which will partially mediate the positive effect of ICT on call center training. This leads to the following hypothesis: H4: Selective hiring will partially mediate the relationship between ICT and initial training, informal learning in the first year, and ongoing training. 


\section{Data, Measures, and Descriptive Statistics}

To test the hypotheses mentioned above, we employ data from the Global Call Center Project, which is based on surveys administered to call center managers in 17 countries around the world in the period 2003-2005. We use the information available for Austria, Brazil, Canada, Denmark, France, Germany, Ireland, Israel, Korea, Poland, Spain, Sweden, United Kingdom, and the United States. For three countries (South-Africa, India, and the Netherlands), the information on key variables like call center training or technologies was insufficient for our analysis. Although the questionnaires were standardized, each country had a slightly different survey and sampling design (Holman, Batt, and Holtgrewe 2007). An overview of the number of cases and response rates per country is given in Table 3.1.

Table 3.1

Number of cases and response rate per country in Global Call Center Project

\begin{tabular}{lcc}
\hline Country & Number of cases & $\begin{array}{c}\text { Response Rate } \\
\%\end{array}$ \\
& & \\
Austria & & 58 \\
Brazil & 96 & 45 \\
Canada & 114 & 77 \\
Denmark & 387 & 65 \\
France & 118 & 60 \\
Germany & 210 & 54 \\
Ireland & 153 & 23 \\
Israel & 43 & 100 \\
South-Korea & 80 & 48 \\
Poland & 121 & 67 \\
Spain & 75 & 49 \\
Sweden & 68 & 46 \\
UK & 139 & 40 \\
US & 167 & 68 \\
& 464 & \\
\hline
\end{tabular}

\subsection{Measures}

Our dependent variables all are single-item measures of training in call centers. Initial training is the number of initial training days for call center agents in the first year. It is widely acknowledged that it is not easy to measure informal learning in surveys (cf. 
Bishop 1997; Veum 1995), which is why we use a proxy for informal learning in the first year: the number of weeks it takes full-time agents to become fully competent in their job. Finally, ongoing training is the number of formal training days (including on-line, vendor, classroom or other formal training) for experienced agents per year.

Interaction automation technologies are measured by the mean of two dichotomous items: regular use of VRU or IVR and regular use of speech recognition. Enhanced interaction technologies are measured by the mean of three dichotomous items: regular use of media blending, regular use of electronic CRM, and regular use of webenablement. Workflow automation technologies are specified by the regular use of workflow management.

Selective hiring is defined by the average use of two measures of selection. ${ }^{3}$ The first is an indicator of the use of systematic selection tests, such as psychometric tests or aptitude tests, as research has found that cognitive ability tests are superior selection devices (Terpstra and Rozell 1993). It shows the percentage of call center agents that is selected by using these systematic selection tests. The second is the percentage of applicants actually hired. This is reverse-coded, as organizations that are more selective have lower percentages of applicants hired.

Of course, training and selective hiring are not only influenced by ICT, but by many other job, firm, and worker characteristics (cf. Bishop 1997). We therefore control for a number of characteristics that prior research has shown to be relevant for explaining training. First, the distinction between in-house call centers and subcontractors is

3. The quality of call center agents selected during recruitment could also be measured by their educational backgrounds. As we only have information on the educational level of the typical agent working in the call center, we do not include this information in the index we construct for selective hiring. However, as we think call center agents' educational background is an important determinant for both formal training and informal learning, we include this measure as a control in the analyses. 
important. In-house call centers provide services to their company's own customers, whereas sub-contractors provide services to customers of other companies. In general, in-house call centers offer more training to their call center agents than subcontracting call centers, as the former ones often have better working conditions on the whole (De Grip, Sieben and Van Jaarsveld 2006). However, call center agents working in subcontractors may need more training on new products and services, as they often work for several different customers. Research also shows that call centers mainly provide training on products and services and leave social interaction skills mostly to call center agents' individual resources (such as Frenkel, Tam, Shire, and Korczynski 1999; Thompson and Callaghan 2002). Call center size (defined here as the total number of workers employed in a center) is included, as ample studies show that large firms provide more training than small firms (see for example Bishop 1997; Shields 1998, Lynch and Black 1998). In addition, age of the call center (defined as years since the center was established) is added because younger call centers might be more prone to implement the latest technologies. We also control for the difference between call centers mainly dealing with inbound calls and centers mainly dealing with outbound calls. Inbound calls usually are more complex than outbound calls, because they are more difficult to forecast than outbound calls. Call center agents who make outbound calls often use scripts, which make these conversations more routine work than inbound calls. Job complexity may also be indicated by customer segment (cf. Batt 2000). Call centers serving large business customers usually deal with more complex calls than call centers serving the general public or mass market. We measure primary customer segment in four dichotomous categories: (1) large business or institutions; (2) small business or high margin mass market; (3) general mass market or general public (the omitted category), and (4) centers serving all markets. Finally, we control for call center agents' educational level, which was measured by using country-specific education levels. In order to have a comparable cross-national measure of education, four education levels were classified: (1) no qualification, (2) school up to age 15 or 16 , (3) school up to age 18 (such as, high school equivalent) 
and (4) university degree or equivalent. More information about the measurement of the variables can be found in the Appendix.

\subsection{Descriptive Statistics}

Table 3.2 provides the mean and standard deviation for all variables, whereas Table 3.3 gives the correlation coefficients. On average, entry-level call center agents receive 22 days of initial training. This initial training period is longer than that for clerical workers more generally, with whom call center workers are frequently compared (cf. Belt, Richardson and Webster 2002). Call centers also invest considerably in informal learning in the first year as well. On average, call center agents need 18 weeks to become proficient in their job. Annual ongoing training is considerably lower than initial training: on average, experienced call center agents receive about 10 days of training per year. In general, call centers that provide more initial training for their agents also provide more informal learning in the first year and more ongoing training. The correlation between initial training and informal learning is significantly positive $(\mathrm{r}=.415)$, and the correlation between initial training and ongoing training is $\mathrm{r}=.353$. In addition, the correlation between informal learning and ongoing training is significantly positive, but much lower than the correlation between initial training and informal learning $(\mathrm{r}=.157)$.

\section{Table 3.2}

Mean and standard deviation of variables

\begin{tabular}{|c|c|c|}
\hline Variable & Mean & s.d. \\
\hline \multicolumn{3}{|l|}{ Training } \\
\hline Initial training: (training days for call center agents in first year) & 22.0 & 19.4 \\
\hline Ongoing training (training days for experienced call center agents per year) & 9.8 & 10.6 \\
\hline Informal learning (weeks it takes call center agents to become fully competent in the job) & 17.5 & 16.8 \\
\hline \multicolumn{3}{|l|}{ Technologiesa } \\
\hline Interaction automation technologies & 33.6 & - \\
\hline - VRU or IVR & 32.3 & - \\
\hline - Speech Recognition & 9.5 & - \\
\hline Enhanced interaction technologies & 57.2 & - \\
\hline - Media Blending & 21.8 & - \\
\hline - Electronic CRM & 37.0 & - \\
\hline - Web-enablement & 35.0 & - \\
\hline Workflow automation technologies & 35.6 & - \\
\hline
\end{tabular}


Table 3.2 (continued)

Mean and standard deviation of variables

\begin{tabular}{lr}
\hline Variable & Mean \\
\hline - Work-flow management & s.d. \\
Selective hiring & 35.6 \\
- Percentage of call center agents selected using systematic selection tests & 47.2 \\
- Reverse of percentage of applicants actually hired & 45.9 \\
Controls & 72.2 \\
In-house call centera & 23.7 \\
Size of call center (number of employees) & - \\
Largest volume of calls being inbounda & 67.8 \\
Age of call center (in years) & 191.0 \\
Customer segmenta & 79.5 \\
- large business & 10.9 \\
- small business & 669.5 \\
- mass market & - \\
- all segments & 10.1 \\
Educational level of typical agent ${ }^{\mathrm{a}}$ & 19.1 \\
- no qualifications & 9.5 \\
- school up to age 15 or 16 & 42.9 \\
- school up to age 18 & 26.8 \\
- university degree or equivalent & - \\
\hline
\end{tabular}

${ }^{a}$ Mean refers to the percentage of call centers

About one-third of the call centers use interaction automation technologies, mainly through VRU or IVR. Speech recognition ${ }^{4}$ is not very widespread, about $10 \%$ of the call centers in our sample use this technology. There is a national component to these automation systems, as speech recognition support is not equally well developed in all languages. In addition, practitioners assert that customers' acceptance of automated interactions differs between countries, which is generally the case for new technologies (Porter 1990). Enhanced interaction technologies are more universal: 57\% of call centers utilize media blending, electronic CRM, or web-enablement. The automation of work processes is also frequent, with an average of $36 \%$ of call centers using workflow management tools. With respect to selection procedures, the average call center is relatively selective - hiring $28 \%$ of applicants, or somewhat more than one for every 4 applicants. Systematic selection tests are used in $46 \%$ of centers.

4. It should be noted that the question about speech recognition in the survey may be a bit misleading, as call center agents normally do not use speech recognition in their interactions with customers. Speech recognition systems are used on the call center level in line with or integrated into VRU/IVR systems (Anton 2000). 


\section{Table 3.3}

Correlations between variables used in paper

\begin{tabular}{|c|c|c|c|c|c|c|c|c|c|c|c|c|c|c|c|c|c|c|c|}
\hline & & 1 & 2 & 3 & 4 & 5 & 6 & 7 & 8 & 9 & 10 & 11 & 12 & 13 & 14 & 15 & 16 & 17 & 18 \\
\hline 1 & Initial training (days) & - & & & & & & & & & & & & & & & & & \\
\hline 2 & Ongoing training (days) & .353 & - & & & & & & & & & & & & & & & & \\
\hline 3 & Informal training (weeks) & .415 & .157 & - & & & & & & & & & & & & & & & \\
\hline 4 & Interaction automation technologies & .111 & .108 & .025 & - & & & & & & & & & & & & & & \\
\hline 5 & Enhanced interaction technologies & .044 & .172 & -.008 & .177 & - & & & & & & & & & & & & & \\
\hline 6 & Workflow technologies & .11 & .163 & .042 & .202 & .307 & - & & & & & & & & & & & & \\
\hline 7 & Selective hiring & .194 & .109 & .131 & .044 & .12 & .187 & - & & & & & & & & & & & \\
\hline 8 & In-house call center (yes/no) & .181 & -.017 & .180 & .036 & -.077 & -.051 & .034 & - & & & & & & & & & & \\
\hline 9 & Size of call center & .052 & .087 & .010 & .162 & .175 & .132 & .018 & -.135 & - & & & & & & & & & \\
\hline 10 & Largest volume of calls & .288 & .060 & .232 & .156 & .000 & .074 & .058 & .331 & .035 & - & & & & & & & & \\
\hline 11 & Age (in years) & .012 & -.043 & .122 & .061 & .006 & -.067 & -.038 & .135 & -.028 & .050 & - & & & & & & & \\
\hline 12 & Segment; large business & -.037 & -.026 & -.027 & -.071 & .085 & -.012 & -.014 & -.142 & .001 & -.167 & .009 & - & & & & & & \\
\hline 13 & Segment: small business & -.008 & -.014 & .023 & -.049 & .029 & -.025 & -.003 & -.006 & -.051 & -.040 & .002 & -.157 & - & & & & & \\
\hline 14 & Segment: mass market & .045 & .029 & .005 & .110 & -.052 & .065 & -.008 & .112 & .088 & .138 & -.077 & -.421 & -.280 & - & & & & \\
\hline 15 & Segment: all segments & -.013 & .004 & .000 & -.016 & -.030 & -.045 & .017 & -.002 & -.057 & .026 & .088 & -.294 & -.195 & -.523 & - & & & \\
\hline 16 & Education: no qualifications & -.005 & -.033 & .025 & -.036 & -.041 & .003 & -.046 & .024 & -.019 & -.013 & .019 & -.018 & .026 & -.003 & -.005 & - & & \\
\hline 17 & Education: to age $15-16$ & -.079 & .021 & -.050 & .024 & .042 & .046 & -.031 & -.063 & .124 & -.026 & .019 & .007 & -.046 & .024 & -.006 & -.068 & - & \\
\hline 18 & Education: to age 18 & -.007 & -.014 & -.005 & .020 & -.087 & -.017 & -.025 & -.046 & -.048 & .030 & -.013 & -.064 & .005 & -.012 & .080 & -.102 & -.601 & - \\
\hline 19 & Education: university degree & .095 & .001 & .050 & -.041 & .068 & -.027 & .073 & .116 & -.072 & -.005 & -.010 & .074 & .037 & -.011 & -.087 & -.058 & -.344 & -.517 \\
\hline
\end{tabular}

Correlations greater than .044 are significant at $p=.05$ or below. 
Table 3.4

Results of negative binomial regression analyses on number of initial training days in first year

\begin{tabular}{|c|c|c|c|c|}
\hline & Model A & Model B & Model C & Model D \\
\hline \multicolumn{5}{|l|}{ Technologies } \\
\hline Interaction automation technologies ${ }^{\mathrm{a}}$ & $.137(.054)^{* *}$ & $.101(.055)^{*}$ & $.069(.072)$ & $.036(.073)$ \\
\hline Enhanced interaction technologies & $.077(.059)$ & $.068(.059)$ & $.029(.073)$ & $.007(.074)$ \\
\hline Workflow automation technologies & - & - & $.166(.049)^{* * *}$ & $.152(.049)^{* * *}$ \\
\hline \multicolumn{5}{|l|}{ Selective hiring } \\
\hline Selective hiring & - & $.003(.001)^{* * *}$ & - & $.003(.001)^{* * *}$ \\
\hline \multicolumn{5}{|l|}{ Controls } \\
\hline In-house call center & $.239(.045)^{* * *}$ & $.237(.045)^{* * *}$ & $.228(.049)$ & $.227(.049)^{* * *}$ \\
\hline Size of call center (\# of employees in '00s) & $-.001(.003)$ & $-.001(.003)$ & $-.001(.003)$ & $-.001(.003)$ \\
\hline Largest volume of calls inbound & $.481(.051)^{* * *}$ & $.470(.050)^{* * *}$ & $.472(.056)^{* * *}$ & $.453(.056)^{* * *}$ \\
\hline Age of call center (in years) & $.003(.002)$ & $.004(.002)^{*}$ & $.002(.002)$ & $.003(.002)$ \\
\hline - large business & $.039(.053)$ & $.030(.053)$ & $.001(.060)$ & $-.012(.060)$ \\
\hline - small business & $.129(.067)^{*}$ & $.129(.067)^{*}$ & $.134(.076)^{*}$ & $.138(.076)^{*}$ \\
\hline - all segments & $.020(.046)$ & $.006(.046)$ & $.048(.052)$ & $.040(.052)$ \\
\hline \multicolumn{5}{|l|}{ Education level of typical agent } \\
\hline - no qualifications & $-.100(.188)$ & $-.252(.197)$ & $-.131(.188)$ & $-.260(.197)$ \\
\hline - school up to age 15 or 16 & $-.075(.052)$ & $-.079(.052)$ & $.002(.064)$ & $.010(.065)$ \\
\hline - university degree or equivalent & $.152(.051)^{* * * *}$ & $.121(.051)^{* *}$ & $.124(.058)^{* * *}$ & $.085(.059)$ \\
\hline Country dummies & Included & Included & Included & Included \\
\hline Constant & $2.177(.086)^{* * *}$ & $2.050(.090)^{* * *}$ & $2.511(.078)$ & $2.387(.083)^{* * *}$ \\
\hline Log likelihood (n) & $-7473.5(1865)$ & $-7319.5(1830)$ & $-5839.8(1451)$ & $-5702.0(1419)$ \\
\hline
\end{tabular}

Models A and B: all countries; Models C and D: all countries without US

a For US, interaction automation technologies only include use of VRU/IVR; ${ }^{*} p<.100 ;{ }^{* *} p<.050 ;{ }^{* * *} p<.010$; - not included in analysis 
Looking at the control variables in our analyses, we see that $68 \%$ of the call centers in our sample are in-house centers providing services to their own company. Call centers, on average, employ a total number of about 190 workers. Furthermore, we distinguish between call centers that mainly deal with inbound calls (80\%) and call centers that handle outbound calls (20\%). $43 \%$ of the call centers in our sample serve the general public or mass market, whereas $19 \%$ of the call centers serve large business customers and $10 \%$ serve small businesses. Finally, we include the educational background of the typical employee in the analyses. Most call centers (48\%) report that the typical call center agent followed schooling up to the age of 18 . In addition $23 \%$ employs call center agents who typically have a university degree or equivalent. This means that call center workforce has higher educational profiles than is commonly pictured in popular accounts

\subsection{Results}

In order to see how different types of ICT and selective hiring are related to training in call centers, we performed negative binomial regression analyses, which take account of the fact that our dependent training variables are left censored count data (Gardner, Mulvey, and Shaw 1995). First, we discuss the estimation results for initial training, followed by the results for informal learning in the first year and for ongoing training, respectively. Tables 3.4, 3.6, and 3.7 in which we present the estimation results of these analyses have the same structure: The first column shows the estimation results of the relationship between technologies used and training (Model A). In the next column we include selective hiring in the analyses (Model B) in order to examine whether this has a mediating effect on the relationship between ICT and training. Moreover, as we do not have data on the workflow automation technologies used by US call centers, we first show these estimation results for all countries we have in our dataset without the workflow automation variable. Then, we present the estimation results of analyses without the US in which we included the workflow automation technologies. Again, we first show the results for the relationships between 
ICT and training (Model C), followed by the results of analyses in which we include selective hiring (Model D).

Of course, for selective hiring to have a mediating effect on the relationship between ICT and training, two other conditions have to be met as well: ICT has to affect selective hiring positively and selective hiring has to positively affect training (cf. Baron and Kenny 1986). We check whether these conditions are met by performing additional regression analyses, of which the results will be reported in a separate table. In all models, we include the control variables discussed in the previous section. In addition, we control for country-specificity by including country dummies. ${ }^{5}$

\subsection{Initial Training}

The results of the negative binomial regression analyses for initial training are presented in Table 3.4. We see in Model A that interaction automation technologies are positively related to the number of initial training days of call center agents. This indicates that VRU/IVR and speech recognition systems in call centers take care of simple, repetitive tasks while leaving the more complex tasks to call center agents, thereby increasing the demand for skill and training needs (cf. Richardson and Gillespie 2003). Enhanced interaction technologies are not significantly related to initial training, however. This is contrary to what we expected in hypothesis $\mathrm{H} 3$. However, it might be explained by observations from our case studies that new agents are assigned to relatively simple tasks and that the full complexity of call center systems is mainly affecting experienced agents. Model B shows that selective hiring has a highly significant positive relationship with agents' level of initial training. More severe selection and recruitment practices thus lead to a workforce with a higher trainability. As we expected, the inclusion of selective hiring in the analysis decreases

5. Another way to control for this country specificity would be to use hierarchical models in which call centers are nested within countries. However, our theoretical model does not include any predictions on specific country-level effects. 
the parameters of the technology variables. This hints at a possible mediation effect, and we will come back to this issue in a moment. First, however, we exclude the US and introduce workflow technology in model C. Here we see that it is rather workflow automation than the other technologies that is positively associated with initial training. The impact of enhanced interaction technologies remains irrelevant, and the effect of interaction automation technologies becomes insignificant. To make sure that US-specific country effects do not blur these relationships, we also ran a regression without workflow technologies excluding the US. However, the effects found are stable. ${ }^{6}$ The effect of the introduction of workflow automation technologies reducing the estimated coefficients for the other call center technologies may be due to the fact that workflow systems often integrate different technologies into one system (CRM, fax, email, Voice over IP, Internet). Moreover, interaction automation technologies often are centrally administered, whereas it is customer service agents that usually are the users of the workflow systems. Therefore, the association between workflow automation and training requirements could be expected to be stronger than the association between interaction automation technologies and training.

Finally, Model D shows again that selective hiring slightly reduces the relationships between call center technologies and call center agents' participation in initial training. Workflow automation is the only technology remaining to have a significant relationship with initial training (hypothesis $\mathrm{H} 2$ ), and this effect diminishes by about $8 \%$ after including selective hiring in the analyses. In order to establish whether selective hiring really has a partial mediating effect on the relationship between ICT and training, we look at the results of additional analyses presented in Table 3.5. Panel A gives the results of an OLS regression analyses on selective hiring, first for all countries without the workflow automation variable (Model 1) and then for all countries except for the US including workflow automation technologies (Model 2). The results show that call centers that implement more ICT are more selective in their

6. Estimation results can be obtained from the authors on request. 
hiring and recruitment strategies. Like in the models $\mathrm{C}$ and $\mathrm{D}$ described above, workflow technologies seem to suppress the effects of interaction automation technologies and enhanced interaction technologies (see Model 2), but all in all, we can conclude that the first additional condition for mediation is met: call center technologies are positively related to selective hiring. Subsequently, in panel B, we see that selective hiring has a positive relationship with initial training. As this substantiates the second additional condition, we can say that selection partially mediates the relationship between the call center technologies used and initial training, thereby confirming hypothesis $\mathrm{H} 4$.

The estimation results in Table 3.4 further show that in-house call centers provide more initial training to their call center agents than subcontractors (cf. De Grip, Sieben and Van Jaarsveld 2006). Participation in initial training is also higher in call centers that mainly deal with inbound calls, and in call centers that serve small business customers. Moreover, call centers that employ agents with university degrees offer more initial training than call centers with lower qualified agents. This shows that initial call center training is not a substitute for initial education; on the contrary, call center training is a complement to education (cf. Thurow 1975; Heckman 2000). Furthermore, the number of training days in the first year does not depend on the size of the call center, which is quite remarkable as ample research shows that larger firms usually provide more training (e.g. Bishop, 1997). In addition, we did not find any effects of the age of the call center. 
Table 3.5

Results of additional regression analyses

\begin{tabular}{|c|c|c|c|}
\hline & $\begin{array}{l}\text { Model 1: } \\
\text { all countries }\end{array}$ & $\begin{array}{l}\text { Model 2: } \\
\text { without US }\end{array}$ & \\
\hline \multicolumn{4}{|l|}{ Technologies } \\
\hline Interaction automation technologies ${ }^{a}$ & $3.896(2.011) *$ & $1.593(2.691)$ & \\
\hline Enhanced interaction technologies & $5.754(2.135) * * *$ & $5.578(2.622) * *$ & \\
\hline Workflow automation technologies & - & $7.670(1.770)^{* * *}$ & \\
\hline Controls and country dummies & included & included & \\
\hline Constant & $43.200(3.083) * * *$ & $45.443(2.764) * * *$ & \\
\hline $\mathrm{R} 2(\mathrm{n})$ & $.094(1867)$ & $.131(1450)$ & \\
\hline \multicolumn{4}{|c|}{ Panel B: Results of negative binomial regression analyses on training } \\
\hline & Analysis 1: & Analysis 2: & Analysis 3: \\
\hline & Initial training & Informal training & Ongoing training \\
\hline Selective hiring & $.003(.001)^{* * *}$ & $.003(.001)^{* * *}$ & $.003(.001)^{* * *}$ \\
\hline Controls and country dummies & included & included & included \\
\hline Constant & $2.117(.084)^{* * *}$ & $1.916(.088)^{* * *}$ & $2.197(.094)^{* * *}$ \\
\hline Log likelihood (n) & $-7498.2(1875)$ & $-7069.6(1884)$ & $-5955.8(1835)$ \\
\hline
\end{tabular}

\subsection{Informal Learning in the First Year}

Table 3.6 shows the results of the negative binomial regression analyses on informal call center learning, which is required to make new call center agents fully competent for their jobs. The estimation results show that enhanced interaction technologies do not affect the extent of informal training in call centers. In addition, there is a negative relationship between interaction automation technologies and informal learning in the first year. This is not in line with our expectations formulated in hypothesis H1 and also contrasts the positive relationship found between interaction automation technologies and initial formal training. A possible explanation for this could be that where initial training needs are higher because of the automation of simple interactions, the need for informal training in the first year is lower because interaction automation systems can be used to separate incoming calls by level of 
complexity and to assign agents to jobs with different skill requirements, thereby narrowing the job content for the newly hired agent.

Including workflow automation technologies in Model C, we see that this technology has a significant positive relationship with informal learning in call centers. This resembles our conclusions on the relationship between ICT and initial training. Both the extent of initial formal training and of initial informal learning are positively affected by the use of workflow automation only. In addition, Model D shows that selective hiring decreases the parameter of workflow automation technologies. As we also established a positive relationship between selective hiring and the extent of informal learning (see Panel B in Table 3.5), we can conclude that selective hiring also has a partially mediating effect on the relationship between these technologies and the extent of informal learning. This confirms our last hypothesis. The relationship with workflow automation decreases by $17 \%$, which is substantially higher than the partial mediating effect of selective hiring on initial formal training.

The estimation results for the control variables to a large extent reflect the estimation results of the analysis on the determinants of initial training. 
Table 3.6

Results of negative binomial regression analyses on informal learning: weeks to become fully competent

\begin{tabular}{|c|c|c|c|c|}
\hline & Model A & Model B & Model C & Model D \\
\hline \multicolumn{5}{|l|}{ Technologies } \\
\hline Interaction automation technologiesa & $-.125(.056)^{* *}$ & $-.153(.057)^{* * *}$ & $-.191(.075)^{* *}$ & $-.208(.077)^{* * * *}$ \\
\hline Enhanced interaction technologies & $.016(.061)$ & $-.007(.062)$ & $-.025(.074)$ & $-.065(.075)$ \\
\hline Workflow automation technologies & & & $.126(.050)^{* *}$ & $.104(.050)^{* *}$ \\
\hline \multicolumn{5}{|l|}{ Selective hiring } \\
\hline Selective hiring & - & $.003(.001)^{* * * *}$ & - & $.003(.001)^{* * * *}$ \\
\hline \multicolumn{5}{|l|}{ Controls } \\
\hline In-house call center & $.304(.047)^{* * *}$ & $.291(.048)^{* * *}$ & $.286(.051)^{* * *}$ & $.271(.052)^{* * *}$ \\
\hline Size of call center (\# of employees in '00s) & $-.003(.003)$ & $-.002(.003)$ & $-.003(.003)$ & $-.002(.003)$ \\
\hline Largest volume of calls inbound & $.367(.053)^{* * *}$ & $.366(.053)^{* * *}$ & $.401(.058)^{* * *}$ & $.393(.059)^{* * *}$ \\
\hline Age of call center (in years) & $.010(.002)^{* * * *}$ & $.011(.002)^{* * * *}$ & $.010(.003)^{* * * *}$ & $.011(.003)^{* * * *}$ \\
\hline \multicolumn{5}{|l|}{ Customer segment } \\
\hline - large business & $-.021(.055)$ & $-.041(.055)$ & $-.059(.061)$ & $-.078(.062)$ \\
\hline - small business & $.109(.069)$ & $.107(.069)$ & $.056(.077)$ & $.060(.078)$ \\
\hline - all segments & $.052(.048)$ & $.036(.048)$ & $.032(.053)$ & $.019(.054)$ \\
\hline \multicolumn{5}{|l|}{ Education of typical CSR } \\
\hline - no qualifications & $-.083(.190)$ & $-.052(.199)$ & $-.061(.187)$ & $-.017(.197)$ \\
\hline - school up to age 15 or 16 & $-.117(.054)^{* * *}$ & $-.094(.054)^{*}$ & $-.018(.065)$ & $.017(.066)$ \\
\hline - university degree or equivalent & $.050(.053)$ & $.054(.054)$ & $.057(.060)$ & $.062(.061)$ \\
\hline Country dummies & Included & Included & Included & Included \\
\hline Constant & $2.143(.089)^{* * *}$ & $1.995(.095)^{* * *}$ & $2.435(.078)^{* * * *}$ & $2.303(.086)^{* * * *}$ \\
\hline Log likelihood (n) & $-7054.7(1879)$ & $-6895.4(1840)$ & $-5451.7(1464)$ & $-5309.1(1428)$ \\
\hline
\end{tabular}

Models A and B: all countries; Models C and D: all countries without US

a For US, interaction automation technologies only include use of VRU/IVR; ${ }^{*} p<.100 ;{ }^{* *} p<.050 ;{ }^{* * *} p<.010$; - not included in analysis 
Newly hired call center agents employed by in-house call centers have longer periods of informal learning than those working for subcontractors. The same holds for agents recruited by call centers that mainly handle inbound calls. However, we do not find that higher educated agents are more involved in informal learning in the first year. This shows that informal learning is neither a complement to nor a substitute for initial education. Finally, we find that call centers that are in business for a longer period of time have higher levels of informal learning in the first year.

\subsection{Ongoing Training}

Finally, the results of the analyses on the number of formal training days for experienced call center agents are displayed in Table 3.7. In Model A, we see that enhanced interaction technologies are positively related to participation in ongoing training, whereas the estimates for interaction automation technologies are not significant. However, a model that excludes the US from this analysis shows a positive effect of interaction automation technologies on ongoing training as well. This indicates that interaction automation technologies are used differently in the US than in the rest of our sample. First, interaction automation technologies are more widely used in the US: $41 \%$ of American call centers employ these technologies compared to on average $7 \%$ of the call centers in the other countries studied here. Secondly, information from our case studies shows that in the US, interaction automation technologies are used to create more narrow jobs with lower skill requirements in specialized call centers, whereas this is not the case in other countries. Model B indicates that selective hiring has a positive impact on ongoing training (which is also confirmed in Panel B in Table 3.5). Furthermore, we can conclude that selective hiring partially mediates the relationship between enhanced interaction technologies and ongoing training, as the effect of enhanced interaction technologies on ongoing training decreases by $39 \%$.

However, when we include workflow automation in the analysis, we find that all three call center technologies are positively associated with call center agents' participation 
in ongoing training (see Model C). Our estimation results therefore confirm the three hypotheses with respect to positive influences of call center technologies on ongoing training. When we compare these estimation results with those presented in Table 3.4 , it is interesting to see that agents' participation in ongoing training is more affected by call center technologies than their participation in initial training. Model $\mathrm{D}$ shows that selective hiring again partially mediates the relationships between the call center technologies and ongoing training (hypothesis H4), as it slightly reduces the effects of interaction automation technologies and enhanced interaction technologies, by $4 \%$ and $4 \%$, respectively. However, the effect of workflow automation is reduced by $24 \%$ and even becomes insignificant. This suggests that selective hiring completely mediates the relationship between workflow automation and ongoing training (cf. Baron and Kenny 1986).

Furthermore, the estimation results show that call center agents' participation in ongoing training is negatively correlated to the age of the call center. This contrasts the positive relationship we found between the age of a call center and the participation in informal learning in the first year. In addition, agents working in call centers that serve small business customers provide somewhat more ongoing training. On the other hand, the number of formal training days for experienced agents is not related to the type of call center: in-house call centers or call centers mainly handling inbound calls do not provide more ongoing training than subcontractors or call centers mainly handling outbound calls. Clearly, all agents employed by a call center need ongoing training on product or service updates, etc. In addition, we did not find a significant relationship with the size of the call center. However, call centers that employ agents with schooling up to age 15 or 16 offer less ongoing training than call centers with agents having high school equivalent qualifications. This shows that ongoing call center training to some extent is a complement to initial education. 
Table 3.7

Results of negative binomial regression analyses on number of ongoing training days after the first year

\begin{tabular}{|c|c|c|c|c|}
\hline & Model A & Model B & Model C & Model D \\
\hline \multicolumn{5}{|l|}{ Technologies } \\
\hline Interaction automation technologies ${ }^{a}$ & $.049(.061)$ & $.030(.062)$ & $.227(.084)^{* * * *}$ & $.217(.086)^{* *}$ \\
\hline Enhanced interaction technologies & $.318(.066)^{* * *}$ & $.309(.067)^{* * *}$ & $.232(.082)^{* * * *}$ & $.223(.083)^{* * *}$ \\
\hline Workflow automation technologies & - & - & $.104(.054)^{*}$ & $.078(.055)$ \\
\hline \multicolumn{5}{|l|}{ Selective hiring } \\
\hline Selective hiring & - & $.003(.001)^{* * *}$ & - & $.003(.001)^{* * * *}$ \\
\hline \multicolumn{5}{|l|}{ Controls } \\
\hline In-house call center & $.022(.050)$ & $.029(.050)$ & $.076(.055)$ & $.084(.055)$ \\
\hline Size of call center (\# of employees in '00s) & $-.000(.004)$ & $.000(.004)$ & $-.004(.004)$ & $-.004(.004)$ \\
\hline Largest volume of calls inbound & $.025(.055)$ & $.011(.055)$ & $.068(.062)$ & $.045(.062)$ \\
\hline Age of call center (in years) & $-.000(.002)$ & $-.001(.002)$ & $-.007(.003)^{* * *}$ & $-.007(.003)^{* * * *}$ \\
\hline \multicolumn{5}{|l|}{ Customer segment } \\
\hline - large business & $-.086(.058)$ & & $-.097(.067)$ & $-.109(.067)$ \\
\hline - small business & $.086(.074)$ & $.073(.074)$ & $.131(.084)$ & $.111(.085)$ \\
\hline - all segments & $.111(.051)^{* *}$ & $.105(.052)^{* *}$ & $.114(.058)^{*}$ & $.105(.059)^{*}$ \\
\hline \multicolumn{5}{|l|}{ Education of typical CSR } \\
\hline - no qualifications & $-.282(.213)$ & $-.293(.223)$ & $-.307(.215)$ & $-.296(.226)$ \\
\hline - school up to age 15 or 16 & $-.126(.057)^{* *}$ & $-.126(.058)^{* *}$ & $-.153(.072)^{* * *}$ & $-.145(.073)^{* * *}$ \\
\hline - university degree or equivalent & $-.047(.058)$ & $-.062(.059)$ & $-.037(.066)$ & $-.060(.068)$ \\
\hline Country dummies & Included & Included & Included & Included \\
\hline Constant & $2.195(.094)^{* * *}$ & $2.074(.099)^{* * *}$ & $1.998(.089)^{* * *}$ & $1.877(.096)^{* * *}$ \\
\hline Log likelihood (n) & $-5947.5(1831)$ & $-5822.0(1795)$ & $-4584.4(1426)$ & $-4471.7(1393)$ \\
\hline
\end{tabular}

Models A and B: all countries; Models C and D: all countries without US

a For US, interaction automation technologies only include use of VRU/IVR; ${ }^{*} \mathrm{p}<.100$; ${ }^{* *} \mathrm{p}<.050 ;{ }^{* * *} \mathrm{p}<.010$; - not included in analysis 


\section{Discussion and Conclusions}

The main objective of this paper was to explore the relationships between different kinds of training for both newly hired workers (initial formal training and informal learning in the first year) and more experienced workers (ongoing formal training) and one of the most important factors shaping production processes in call centers: information and communication technology. In addition, we studied the mediating effect of selective hiring on these relationships.

In general, ICT could affect call center training in two ways. On the one hand, technologies may substitute employees who perform limited and well-defined tasks (Cooley 1986; Shaiken 1985). On the other hand, ICT could complement work processes that involve more difficult tasks (Kern and Schuhmann 1984). In both cases, ICT would be related to an increase in the demand for skill and thus higher training needs. This is exactly what we find in call centers, although not all types of technologies are associated to more training.

First, interaction automation technologies, such as Voice Response Units (VRU) and Interactive Voice Response (IVR) systems and speech recognition, have a positive relationship with ongoing training. This suggests that these automation technologies take away the more simple, repetitive tasks, while leaving the complex tasks to be handled by call center agents (cf. Richardson and Gillespie 2003). However, interaction automation technologies do not affect initial formal training, and have a negative relationship with informal learning in the first year. This suggests that these technologies in some cases are used to create more narrow jobs for newly hired agents.

Enhanced interaction technologies, such as media blending, electronic customer relationship management and web-enablement, also positively influence the number of formal training days experienced call center agents receive. This is probably caused by the fact that agents must learn more techniques and skills to master these technologies. It is therefore remarkable that we observed no 
relationship between the enhanced interaction technologies and initial formal training or informal learning. It may be that call centers only offer more training induced by these complex technologies in a later career stage, when agents are more mature in their work and can draw upon their earlier experiences. Another explanation could be that system changes related to advanced technologies require substantial skill changes, which increase the need for ongoing training. Observations from our case studies support the latter view.

Finally, workflow automation, which is used in call centers to automate and standardize work processes, has a positive association with all types of training studied in this paper. Call centers employing workflow automation technologies offer significantly more initial training, more informal learning in the first year, and more ongoing training to their call center agents than call centers that do not use these technologies. This implies that workflow automation in call centers is utilized to increase the ability to handle complex tasks that involve several agents and repeated customer interactions and not as a way to create more narrow and standardized jobs.

All in all, our three hypotheses predicting a positive relationship between the different types of call center technologies and initial training, informal learning in the first year, and ongoing training, are only partly confirmed. Obviously, it is particularly workflow technologies that generate training demands in call centers, whereas interaction automation technologies and enhanced interaction technologies only lead to more ongoing training. On the one hand, this corroborates the more generic literature that ICT leads to higher demand for skill and therefore to more training (Autor, Levy and Murnane 2003). On the other hand, it shows that specific technologies have different effects on training demands.

\subsection{Mediating effect of selective hiring}

We argued that call centers with high training demands induced by high levels of technology will have more severe selection and recruitment practices. By selecting high quality employees, firms recruit a workforce that is expected to have high 
returns on further training and more commitment to stay with the firm. We found that there indeed is a positive relationship between selective hiring and both initial and ongoing formal training and informal learning in the first year. This indicates that both formal training and informal learning complements call center agents' initial abilities.

Moreover, the inclusion of selective hiring in the analyses decreased the estimated significant effects of the use of advanced technologies on initial training, informal learning in the first year, and ongoing training. As additional analyses showed positive relationships between the call center technologies and selective hiring, this shows that there is a partial mediating effect of selective hiring on the relationship between ICT and training, as was expected in our fourth hypothesis. It should, however, be noted that this mediating effect usually is not very high, as the effects of workflow automation on training decrease by about $8 \%$ for initial training and by $17 \%$ for informal learning in the first year, and still are significant after the inclusion of selective hiring. Only for ongoing training, selective hiring completely mediates the relationship with workflow automation technologies.

\subsection{Future research}

Although our analyses are based on a very extensive dataset including 14 countries, we were only able to relate training to call center technologies and selective hiring in a cross-sectional analysis. This means that we were unable to deal with the possibility that firms that provide more training might also be inclined to invest more in ICT. However, although this reverse causality could be possible, we think it is not that important in the call center sector. Call centers are relatively new operations that highly depend on the implementation of state of the art technologies and generally start with the choice of the most advanced and reliable ICT. In addition, in a cross-sectional design, it is not possible to analyze any changes associated with the introduction of new technologies in call centers. Future research should therefore focus on developing longitudinal data. This would also facilitate research on the assertion that the introduction of the ITC-based call center production model has initiated a new division of labor that over time has 
lead to decrease the demand for skill for specific occupational groups which have been transferred from traditionally organized service jobs to call center jobs (cf. Batt, Hunter and Wilk 2003). Such an analysis would require a longitudinal study as well or a study of specific occupations across sectors.

In addition, future research might include domain specific technologies. These technologies refer to the complexity of the products for which the call center is providing services. This complexity is related to inherent characteristics of products (product scope) and to the number and variety of products supported (product scale). It is not difficult to imagine that more complex products and related ICT systems raise the demand for skill and training needs for call center agents. We therefore suggest developing data on the frequency of product updates, extensiveness of agent's product portfolio, and the quantity of product documentation.

Finally, future research should focus on the relationships between ICT, the demand for skill, and the off shoring of call center services. The discussion and results about the impact of call center technologies on training we presented in this paper may leave the reader with the picture that computers substitute simple work tasks, thereby eliminating tedious, repetitive work for call center agents. However, as mentioned before, the fact that computers can perform rule-based calculations does not mean that all simple human tasks in call centers can be substituted. Computers cannot understand the meaning of even simple dialogs, which are not tightly scripted. Therefore, relatively simple, monotonous tasks still have to be performed by agents. To handle this problem, call center managers may choose a strategy to offshore services to low wage countries, which raises the relative demand for skilled workers in the industrialized countries (Levy and Murnane 2004), although it should be noted that in many mostly non-English speaking countries the possibilities of off shoring call center services are limited by the distribution of language competences. 


\section{References}

Acemoglu, Daron (1997), Training and Innovation in an Imperfect Labour Market, Review of Economic Studies, Vol. 64, pp. 445-464.

Anton, Jon (2000), The past, present and future of customer access centers, International Journal of Service Industry Management, Vol. 11, No. 2, pp. 120-130.

Athey, Susan, and Scott Stern (2002), The impact of information technology on emergency health care outcomes, Rand Journal of Economics, Vol. 33, pp. 399-432.

Autor, David H., Lawrence .F. Katz and Alan B. Krueger (1998), Computing Inequality: Have Computers Changed the Labor Market?, Quarterly Journal of Economics, Vol. 113, pp.10551089.

Autor, David H., Frank Levy, and Richard J. Murnane (2003), The Skill Content Of Recent Technological Change: An Empirical Exploration, Quarterly Journal of Economics, Vol. 118, pp. 1279-1333.

Baldwin John, Tara Gray and Joanne Johnson (1995), Technology Use, Training and Plant Specific Knowledge in Manufacturing Plants, Analytical Studies Branch Statistics Canada, Research Paper Series, no. 86.

Baldwin, John and Valerie Peters (2001), Training as a Human Resource Strategy: The Response to Staff Shortages and Technological Change. Analytical Study Branch Statistic Canada, Research Paper Series, no 154.

Baron, Reuben and David Kenny (1986), The moderator-mediator variable distinction in social psychological research, Journal of Personality and Social Psychology, Vol. 51, pp. 1173-82.

Bartel, Ann P. and Nachum Sicherman (1998), Technological Change an the Skill Acquisition of Young Workers, Journal of Labor Economics, Vol. 7, pp. 1-19.

Batt, Rosemary, (2000), Strategic Segmentation in Front-line Services: Matching Customers, Employees, and Human Resource Systems, International Journal of Human Resource Management, Vol. 11, pp. 540-561.

Batt, Rosemary, Larry W. Hunter, and Steffanie Wilk (2003), How and When Does Management Matter? Job Quality and Career Opportunities for Call Center Workers, in: Eileen Appelbaum, Anette Bernhardt, and Richard J. Murnane (eds), Low-Wage America. How Employers Are Reshaping Opportunity in the Workplace, New York: Russell Sage Foundation, pp. 270-313.

Becker, Brian E. and Mark A. Huselid, Overview: Strategic Human Resource Management in five leading firms, Human Resource Management, Vol. 38, pp.287-301.

Belt, Vicky, Ranald Richardson, and Juliet Webster (2002), Women, social skills and interactive service work in telephone call centers, New Technology, Work and Employment, Vol. 17, No. 1, pp. 20-34. 
Bishop, John H. (1997), What We Know About Employer-Provided Training: A Review of the Literature, Research in Labor Economics, Vol. 16, pp. 19-87.

Bresnahan, Timothy F., Erik Brynjolfsson, and Lorin M. Hitt (2002), Information Technology, Workplace Organization, and the Demand for Skilled Labor: Firm-Level Evidence, Quarterly Journal of Economics, Vol. 117, pp. 339-376.

Brunello, Giorgio , Pietro Garibaldi, and Etienne Wasmer (2006), Education and Training in Europe, Oxford: Oxford University Press.

Brynjolfsson Erik and Lorin Hitt.(1998), Information Technology and Organizational Design: Evidence from Micro Data. MIT, Sloan School of Management, mimeo.

Callaghan, George, and Paul Thompson (2002), We recruit attitude: The selection and shaping of routine call centre labour, Journal of Management Studies, Vol. 39, pp. 233-254.

Cena, Federica, and Iliaria Torre (2006), Adapting the interaction in a call centre system, Interacting with Computers, Vol. 18, pp. 478-506.

Cooley, Mike (1986), Architect or Bee, London: Abacus.

Deery, Stephen, and Nick Kinnie (2004), Call Centres and Human Resource Management. A Cross-National Perspective, Houdmills, New York: Palgrave Macmillan.

De Grip, Andries, Inge Sieben, and Danielle Van Jaarsveld (2006), Labour Market Segmentation Revisited: A study of the Dutch Call Centre Sector, Maastricht: Research Centre for Education and the Labour Market.

Doms, Mark, Timothy Dunne, and Kenneth R. Troske (1997), Workers, wages, and technology, Quarterly Journal of Economics, Vol. 112, pp. 253-290.

Fernie, Sue, and David Metcalf (1998), (Not) Hanging on the Telephone: Payment Systems in the New Sweatshops, London: Centre for Economic Performance, LSE.

Frenkel, Stephen J., May Tam, Karen A. Shire, and Marek Korczynski. (1999), On the Front Line: Organization of Work in the Information Society. Ithaca, NY: Cornell University Press.

Gardner, William, Edward Mulvey, and Esther Shaw (1995), Regression analyses of counts and rates: Poisson, overdispersed Poisson, and negative binomial models, Psychological Bulletin, Vol 118, No. 3, pp. 392-404.

Gherardi, Linda. (1999), The impact of technology on call center training, Call Center Solutions, Vol. 18, No. 2, pp. 120-123.

Giuri, Paola, Salvatore Torrisi, and Natalia Zinovyeva (2006), ICT, Skills, and Organisational Change: Evidence from a Panel of Italian Manufacturing Firms. Department of Management, University of Bologna. LEM Working Paper Series, 2005/11.

Goos, Maarten, and Alan Manning (2007), Lousy and Lovely Jobs: The Rising Polarization of Work in Britain, Review of Economics and Statistics, Vol.89, No.1, pp.118-133. 
Groot, Loek F.M., and Andries. de Grip (1991), Technological Change and Skill Formation in the Bank Sector, Economics of Education Review, Vol. 10, pp. 57-71.

Heckman James J. (2000), Policies to foster human capital, Research in Economics, Vol. 54, No. 1, pp. 3-56.

Hempell, Thomas (2003), Do computers call for training? Firm-level Evidence on Complementaries between ICT and Human Capital Investment, ZEW discussion-paper No 03-20.

Hersch, Joni (1991), Education Match and Job Match, Review of Economics and Statistics, Vol. 73, pp. 140-144.

Holman, David, Rosemary Batt, and Ursula Holtgrewe (2007), The Global Call Center Report: International Perspectives on Management and Employment.

Holman, David, Claire Chissick, and Peter Totterdell (2002), The Effects of Performance Monitoring on Emotional Labor and Well-Being in Call Centers, Motivation and Emotion, Vol. 26, pp. 57-81.

Keefe, Jeffrey (1991), Numerically Controlled Machine Tools and Worker Skills, Industrial and Labor Relations Review, Vol. 44, No. 3, pp. 503-519.

Kern, Horst, and Michael Schuhmann (1984), Das Ende der Arbeitsteilung? Rationalisierung in der Industriellen Produktion. Munich: Beck.

Levy, Frank, and Richard J. Murnane (2004), The New Division of Labor: How Computers Are Creating the Next Job Market. Princeton, NJ: Princeton University Press.

Lynch, Lisa M., and Sandra E. Black (1998), Beyond the Incidence of Employer-Provided Training, Industrial and Labor Relations Review, Vol. 52, pp. 64-81.

Osterman, Paul. (1994), How common is workplace transformation and who adopts it?, Industrial and Labor Relations Review, Vol. 47, pp. 173-188.

Osterman, Paul. (2000), Work reorganization in an era of restructuring: Trends in diffusion and effects on employee welfare, Industrial and Labor Relations Review, Vol. 53, pp. 179-196.

Porter, Michael (1990), Competitive Advantage of Nations, New York: Macmillan Press.

Richardson, Ranald, and Andrew Gillespie (2003), The call of the wild: Call centers and economic development in rural areas, Growth and Change, Vol. 34, pp. 87-108.

Shaiken, Harley (1985), Work transformed, New York: Holt, Rinehart and Winston.

Shields, Michael (1998), Changes in the determinants of employer-funded training for full-time employees in Britain, Oxford Bulletin of Economics and Statistics, Vol. 60, pp. 189-214.

Sieben, Inge, and Andries De Grip (2004), Training and expectations on job mobility in the call centres sector, Journal of European Industrial Training, Vol. 28, pp. 257-271. 
Sicherman, Nachum. (1991), 'Overeducation' in the Labor Market, Journal of Labor Economics, Vol. 9, pp. 101-122.

Spenner, Kenneth I. (1985), The upgrading and downgrading of occupations: Issues, evidence, and implications for education, Review of Educational Research, Vol. 55, pp. 124-154.

Spitz-Oener, Alexandra (2006), Technical Change, Job Tasks, and Rising Educational Demands: Looking outside the Wage Structure, Journal of Labor Economics, Vol.24, pp. 235-270.

Suchman, Lucy A. (1999), Plans and situated actions. Cambridge: University Press: Cambridge.

Taylor, Phil, and Peter Bain (1999), 'An Assembly Line in the Head': Work and Employee Relations in the Call Centre. Industrial Relations Journal, Vol. 30, pp. 101-117.

Terpstra, David and Elizabeth Rozell (1993), The relationship of staffing practices to organizational level measures of performance, Personnel Psychology, Vol. 46, pp. 27-48.

Thompson, Paul, and George Callaghan. (2002), Skill Formation in Call Centres. In: Ursula Holtgrewe, Christian Kerst, and Karen Shire (eds)., Re-organizing Service Work. Call Centres in Germany and Britain. Aldershot: Ashgate, pp. 105-122.

Thurow, Lester C. (1975), Generating Inequality. New York: MacMillan.

Van Smoorenburg, Michel, and Rolf van der Velden (2000), The Training of School-Leavers, Complementarity or Substitution?, Economics of Education Review, Vol. 19, No. 2, pp. $207-$ 217.

Veum, Jonathan R. (1995), Sources of Training and Their Impact on Wages, Industrial and Labor Relations Review, Vol. 48, No. 4, pp. 812-826. 


\section{Appendix 1. Variables used in the analyses}

Training

- Initial training: number of initial training days for call center agents in the first year.

- Informal learning: number of weeks it takes full-time call center agents to become fully competent on the job, such as so that they are able to train someone else.

- Ongoing training: number of formal training days for experienced call center agents per year.

ICT

- Interaction automation technologies: index of the mean of two variables:

- Regular use of a Voice Recognition Unit (VRU) or Interactive Voice Response Unit (IVR) (yes/no);

- Regular use of speech recognition by call center agents to interact with customers (yes/no); information not available for the US.

- Enhanced interaction technologies: index constructed out of the mean of three variables:

- Regular use of media blending by call center agents to interact with customers (yes/no);

- Regular use of electronic Customer Relationship Management by call center agents to interact with customers (yes/no);

- Regular use of web-enablement (joint browsing, chat, instant messaging) by call center agents to interact with customers (yes/no).

- Workflow automation technologies: regular use of workflow management by call center agents to interact with customers (yes/no); information not available for the US. 


\section{Selective hiring}

Index constructed out of the mean of two variables:

- Percentage of call center agents that have been selected using systematic selection tests (such as psychometric tests or aptitude tests);

- Inverse of percentage of people who apply for agent jobs at the call center that actually get hired.

\section{Controls}

- In-house call centers: call center described by respondent as an in-house center providing services to own company (as opposed to a subcontractor providing services to other companies - reference category).

- Size of call center: total number of employees, divided by 100 .

- Inbound calls: largest volume at call center being inbound calls (as opposed to largest volume of calls being outbound calls - reference category).

- Age of call center: year of survey minus year in which call center was established.

- Customer segment: segment accounting for the largest volume of customers the call center serves being (a) large business or institutions; (b) small business or high margin mass market; (c) general mass market or general public; or (d) all types of customers.

- Educational level: typical level of call center agents measured in countryspecific qualification levels and subsequently classified into (a) no qualifications; (b) schooling up to age 15 or 16; (c) schooling up to age 18; and (d) university degree or equivalent. 